\title{
TITLE:
}

\section{What to copy: the key factor of observational learning in striped jack (Pseudocaranx dentex) juveniles.}

\author{
$\operatorname{AUTHOR(S):~}$ \\ Takahashi, K; Masuda, R; Yamashita, Y
}

\section{CITATION:}

Takahashi, K ...[et al]. What to copy: the key factor of observational learning in striped jack (Pseudocaranx dentex) juveniles.. Animal cognition 2013, 17(2): 495-501

\section{ISSUE DATE:}

2013-10-04

URL:

http://hdl.handle.net/2433/197329

\section{RIGHT:}

The final publication is available at Springer via http://dx.doi.org/10.1007/s10071-0130686-z; This is not the published version. Please cite only the published version.; この論文 は出版社版でありません。引用の際には出版社版をご確認ご利用ください。 
1 Title: What to copy: the key factor of observational learning in striped jack

2 (Pseudocaranx dentex) juveniles

3

4 Authors: K. Takahashi, R. Masuda, and Y. Yamashita

5

6

$7 \quad$ K. Takahashi (Corresponding author) $\cdot$ R. Masuda · Y. Yamashita

8 Maizuru Fisheries Research Station, Kyoto University, Nagahama, Maizuru,

9 Kyoto, 625-0086, Japan

10 e-mail: tkouji@kais.kyoto-u.ac.jp, tel: + 81-773-62-5512, fax: + 81-773-62-

$11 \quad 5513$

12

13 
14 Abstract

15 Animals in social environments can enhance their learning efficiency by observing

16 the behaviour of others. Our previous study showed that learning efficiency of 17 schooling fish increased through observation of the behaviour of trained 18 demonstrator conspecifics. The present study aimed to verify the key factor of 19 observational learning by investigating what information is important for social 20 transmission of feeding information. A striped jack (Pseudocaranx dentex) observer 21 was provided with one of five observation treatments: (a) pellets observation, 22 where pellets were dropped near the aeration in an adjacent tank; (b) responding 23 conspecific observation, where a trained conspecific demonstrator responded to the 24 aeration without food in the adjacent tank; (c) foraging conspecific observation, 25 where a conspecific demonstrator foraged near the aeration in the adjacent tank; 26 (d) nearby pellets observation, where pellets were dropped in a transparent column 27 near the aeration in the observer tank, and (e) foraging heterospecific observation, 28 where a filefish (Stephanolepis cirrhifer) demonstrator foraged near the aeration in 29 the adjacent tank. The response to the aeration in these observers was compared 30 with that of controls who did not observe any behaviour. Only individuals which 31 observed foraging conspecifics showed a response to the aeration after observing. 32 These results suggest that observer fish acquire feeding information not through 33 recognition of prey items or through imitation of the demonstrator, but through the 34 vicarious reinforcement of a conspecific for foraging.

36 Keywords: behavioural transmission, conditioning, copying, fish cognition, social 37 learning 


\section{Introduction}

Learning in a social environment can potentially be facilitated by social learning (Kleiman and Eisenberg 1973). In social learning, an individual acquires behaviour and information through observations of and interactions with other individuals. This style of learning has the potential to enhance an individual's adaptation to the living environment. For example, prey location can be learned through observations of associating shoal mates in feeding sites, without the energetic expenditure of food searching, e.g., in Atlantic salmon Salmo salar (Brown et al. 2003). The anti-predator behaviour of the Japanese flounder (Paralichtys olivaceus) can also be enhanced through observation of conspecifics, without the risk of predation (Arai et al. 2007).

About half of the teleost fishes in the world live socially in a school for at least part of their lives (Shaw 1978) and thus have the opportunity to acquire information through social learning. Indeed, some studies have found that fish acquire survival skills by social learning in various life history contexts, such as predator avoidance (Brown and Laland 2001; Kelly et al. 2003), orientation behaviour (Warner, 1988; Fukumori et al. 2010), feeding (Reader et al. 2003; Schuster et al. 2006; Webster and Laland 2008), and mate choice (Witte and Nobel 2011).

Social learning mechanisms have been studied in a number of species, including rats (Zohar and Terkel 1991), dogs (Miller et al. 2009), primates (Hopper et al. 2008; Tennie et al. 2010), and birds (Klein and Zentall 2003; McGregor et al. 2006). For example, McGregor et al. (2006) found in pigeons (Columba livia) that, even when demonstrators were not rewarded while being observed, observers of pecking behaviour made pecking responses more frequently than did observers of stepping behaviour. This study provided evidence of imitation simply as a process 
64 in which 'B learns some aspect(s) of the intrinsic form of an act from A' (emphasis

65 original; Hopper 2010). Hopper (2010) also defined 'ghost display' conditioning,

66 where an observer is able to reach a predetermined goal from seeing only the

67 pertinent parts of a given task/apparatus without an active model operating it.

While many researchers have investigated the function of observational

69 learning in fish (i.e. what fishes learn through observation), there are few studies

70 regarding the mechanisms of observational learning (i.e. how fish learn their

71 behaviours through observational learning). Recent studies have shown that their

72 cognitive capacity in many domains is comparable with that of non-human

73 primates (Brown et al. 2011). For example, fishes have evolved complex cultural

74 traditions (Brown and Laland 2011; Bshary et al. 2002), that is, they not only

75 recognize one another, but they can also monitor the social prestige of and

76 dominance relations amongst others (Griffiths 2003; Grosenick et al. 2007). Thus,

77 they may be equipped with mechanisms for the observational learning that are

78 similar to those of animals of higher orders.

Our previous study confirmed the ability for observational learning in jack mackerel (Trachurus japonicus) juveniles: fish that observed other individuals feeding at the aeration in an adjacent tank were conditioned to aeration as a stimulus to initiate feeding more quickly than fish that did not observe this conspecific behaviour (Takahashi et al. 2012a). Here we tried to tease apart the process of observational learning and thus elucidate the essential mechanism of this social behaviour. We proposed their observational learning could be explained by one of the following hypothetical processes: (i) fish are conditioned to aeration with the presence of food through watching the foods and aeration stimulus, which could be confirmed by a 'ghost display condition'; (ii) observer fish copy demonstrator fish in their response to aeration, suggesting that they are capable of 
90 imitation; or (iii) observer fish acquire feeding information by observing

91 demonstrator fish foraging near the aeration, indicating that they need a full

92 demonstration. By testing these conditions separately, this study investigated how

93 observational learning is formed in conditioned feeding with the aeration stimulus.

94 We used striped jack (Pseudocaranx dentex) in this study. They consistently

95 form a school when they attain the juvenile stage at around $20 \mathrm{~mm}$ standard

96 length (SL; Masuda and Tsukamoto 1998) and therefore have many opportunities

97 to acquire information from conspecifics, much like T. japonicus. This species is

98 more resistant to stress from isolation than T. japonicus (Takahashi, personal

99 observation). Furthermore, in this study, we used a heterospecific demonstrator

100 observation treatment to investigate the possibility of observational learning

101 between species. Using a demonstrator fish that has a different shape from that of

102 the observer, the treatment confirmed the importance of the appearance of a model

103 for observational learning. Filefish (Stephanolepis cirrhifer) were used as the

104 heterospecific demonstrators. ALthough they live in sympatry and share feeding

105 resources with $P$. dentex (Masuda, personal observation), the body form is

106 distinctly flat compared with that of $P$. dentex, which is more spindle-shaped.

107

108 Materials and methods

109 Fish

110 Hatchery-reared P. dentex were purchased from Yamasaki Giken Co., Ltd. or

111 Pacific Trading Co., Ltd. and were transported to the Maizuru Fisheries Research

112 Station, Kyoto University. About a hundred juveniles were kept in each of two 5001

113 transparent polyethylene tanks supplied with filtered seawater at a rate of $4 \mathrm{l}$ per

$114 \mathrm{~min}$ and with strong aeration $(600 \mathrm{ml} / \mathrm{min})$. Rearing tanks were indoors, and

115 water temperature was kept at about $25^{\circ} \mathrm{C}$ using a heater and thermostat. The fish 
116 were fed with commercial pellets (Otohime C2 and Otohime S2, Marubeni Nisshin

117 Feed Co., Ltd.) to satiation once or twice a day until the fish were to be used for the

118 experiment. All the fish were kept in a tank for at least one month to be weaned on

119 pellets, as all were confirmed to forage actively on pellets near the water surface.

120 SL of all to fish used was measured after the experiments. Fish mean SL was 76.2

$121 \mathrm{~mm}$ (standard deviation $=1.2 \mathrm{~mm}$ ), and there was no difference between

122 treatments (according to an analysis of variance: $F_{5,44}=1.65, P>0.05$; Table. 1 ).

123 Juveniles used for the experiment ranged in age from 90 to 120 days old. It was not

124 possible to identify sex in these juveniles.

126 Apparatus and Procedure

127 Transparent glass tanks (length $\times$ width $\times$ height: $60 \times 30 \times 35 \mathrm{~cm}$ ) were set up in a

128 temperature-controlled room and covered with black vinyl sheets except for one

129 side. Seawater was continuously added to the experimental tanks and drained

130 using a siphon to maintain a depth of $20 \mathrm{~cm}$. Tanks were separated by a black

131 sheet to reduce disturbance from experimenters. A video camera (HDR-CX550,

132 Sony Co., Tokyo, Japan) above the experimental tank allowed recording of the fish

133 behaviour during the experiment.

134 An air stone was positioned set at the centre of each tank, and aeration was

135 remotely controlled and was turned off except in the conditioning trial, when

136 aeration was set to be gently turned on to provide approximately $12 \mathrm{ml}$ of air per

137 minute. The tanks of the observer fish and the demonstrator fish were arranged so

138 that the uncovered sides of its tanks faced each other, and a removable black board

139 (length $\times$ height: $60 \times 35 \mathrm{~cm}$ ) was placed between tanks except during an 140 observation trial. 
142 used as a demonstrator. All demonstrator fish were conditioned to respond to 143 aeration as a conditioned stimulus and feeding pellets as an unconditioned

144 stimulus, as in Takahashi et al. (2012b); that is, $30 \mathrm{~s}$ after the onset of aeration,

145 pellets were dropped near the aeration. The demonstrators were trained until they

146 showed a prominent response to aeration without pellets. Different demonstrator

147 fish were used for each observer fish, except for the foraging heterospecific

148 observer. Some of the observer fish that had been trained to respond to aeration

149 were used as demonstrators after the test trial, but no demonstrator fish were used 150 as observers.

151 Single fish were randomly selected from each rearing tank, introduced into 152 one of four replicate observer tanks on the previous day, and allowed to acclimate 153 overnight. A few pellets were provided before initiating the experiment, which 154 began once the observer fish ate these initial pellets. When the fish was foraging 155 for the pellets, the black board between the tanks was removed at $30 \mathrm{~min}$ before 156 the start of observation trials so that demonstrator fish were visible to observer 157 fish in the adjacent tank. Observer and demonstrator fish used for an experiment 158 trial were drawn from the same stock tank. Therefore, they were likely to be 159 familiar with each other during the observation trial.

\section{Observation trial}

162 Observer fish were provided with one of the following treatments, performed by 163 demonstrator fish in the adjacent tanks: pellets, responding conspecific, foraging 164 conspecific, nearby pellets, and foraging heterospecific observation (Fig. 1a-e). Five 165 observation trials were provided for each observer, and the observation trial was 166 video recorded to evaluate fish behaviour. The response to aeration of these 167 treatment groups was compared with that of the control group, where no 
168 demonstrator fish was provided (Fig. 1f). Eight fish were used in the control group

169 and in each observational treatment except for the nearby pellets treatment, in 170 which five fish were used.

171 In the pellets treatment, pellets were dropped near the aeration in a 172 demonstrator tank that contained no demonstrator fish. The observation trial 173 lasted for $60 \mathrm{~s}$; after aerating for $30 \mathrm{~s}$, three to five pellets were dropped near the 174 aeration source three times at $15 \mathrm{~s}$ intervals. In the responding conspecific 175 treatment, an observer fish was allowed to observe a $P$. dentex demonstrator that 176 was responding to aeration without pellets. The observational trials ran for $30 \mathrm{~s}$, 177 which was the same as the duration of aeration in the demonstrator tank. In the 178 foraging conspecific observation treatment, the observer fish observed the 179 behaviour of a conspecific demonstrator that was responding to aeration and 180 foraging pellets near it. The observation trials ran for $60 \mathrm{~s}$; after the aeration was 181 turned on for $30 \mathrm{~s}$, three to five pellets were dropped near the aeration three times 182 at $15 \mathrm{~s}$ intervals.

183 The nearby pellets treatment investigated the possibility of observational 184 learning in a situation where the observer can recognize the food at close range 185 within the observer tank, because there was a possibility that during the pellets 186 treatment, observer fish would not be able to recognize the pellets in the adjacent 187 demonstrator tank. In this treatment, the pellets were so that the observer could 188 see them but the fish was not allowed to forage the pellets. A transparent oval 189 column $(10 \mathrm{~cm} \times 7.5 \mathrm{~cm} \times 30 \mathrm{~cm}$ height $)$ was positioned at the centre of the 190 conditioning tank, and the air stone was put outside of the column. An observer 191 was provided with the observation trial for $60 \mathrm{~s}$, during which the aeration was 192 turned on for $30 \mathrm{~s}$, and after that the pellets were dropped into the oval column 193 near the aeration three times at $15 \mathrm{~s}$ intervals. The pellets were removed using a 
194 pipette after turning off the aeration.

To conduct heterospecific observation trials, two S. cirrhifer $(93 \mathrm{~mm}$ and 95 mm SL) were captured using a cage trap in Maizuru Bay $\left(35^{\circ} 49^{\prime} \mathrm{N} ; 135^{\circ} 36^{\prime} \mathrm{E}\right)$ and

197 transported in a bucket of seawater. They were kept in a 5001 transparent

198 polyethylene tank, like that was to the $P$. dentex. Rearing tanks were indoors, and 199 water temperature was kept at about $25^{\circ} \mathrm{C}$ using a heater and thermostat. After 200 confirming active foraging on pellets (Otohime S2) in the water column, they were 201 transferred to two separate tanks. They were trained until both showed prominent 202 responses to aeration, and could thus be used as demonstrators. Five observation 203 trials were conducted in the same manner as the foraging conspecific observer 204 treatment, i.e., after the onset of aeration for $30 \mathrm{~s}$, pellets were dropped near 205 aeration for $30 \mathrm{~s}$. After the experiment, S. cirrhifer were measured in their SL and 206 subsequently released at the capture site.

$207 \quad$ Five observation trials were conducted with about $30 \mathrm{~min}$ intervals for each 208 of the observation treatments. After the fifth trial, the black separation board was 209 placed between observer and demonstrator tanks to avoid further interaction 210 between them; in the nearby pellets treatment, the column was removed from the 211 observer tank. Each observer fish was given a test trial at $30 \mathrm{~min}$ after the fifth 212 observation trial.

214 Test trial

215 A test trial was conducted to confirm the observer fish's response to aeration in 216 observation tank without feeding pellets; aeration was turned on for $1 \mathrm{~min}$. The 217 response was then compared with that of the control group. In the test trial, 218 behaviour of each observer and control was video recorded for $2 \mathrm{~min}, 1$ min pre219 aeration and 1 min post-aeration. 
221 Behavioural analyses

222 Attraction to the demonstrator tank was used as an index of the observation 223 behaviour in the first observation trials except for the nearby pellets treatment.

224 The attraction was measured by the staying duration of fish within $7.5 \mathrm{~cm}$ (approx. 225 one fish SL, and $25 \%$ of experimental tank) from the side of the demonstrator tank. 226 Attraction behaviour was measured for $30 \mathrm{~s}$ in each observation trial: while pellets 227 were dropped near the aeration three times in the pellets treatment, while the 228 aeration of the demonstrator tank was turned on (i.e. demonstrator fish responded 229 to aeration without pellets) in the responding conspecific treatment, and while 230 pellets were dropped near the aeration three times (demonstrator fish foraged near 231 aeration) in the foraging conspecific or heterospecific treatment. The attraction 232 duration to a demonstrator tank was compared among observation treatments 233 using a Kruskal-Wallis test followed by a Steel-Dwass multiple comparison as a 234 post hoc test. The attraction duration to a demonstrator tank in the first 235 observation trial was also compared with $7.5 \mathrm{~s}$ as the significance level (chance 236 level: $25 \%$ of $30 \mathrm{~s}$ ), in each observation treatment using a one-sample Wilcoxon test $237(\mathrm{n}=8)$, because the data were not normally distributed.

238 In the nearby pellets observation treatment, attraction behaviour to pellets 239 was measured using the duration of fish staying near the aeration (within $7.5 \mathrm{~cm}$ 240 around the oval column). The duration was measured to $30 \mathrm{~s}$ in each of the pre241 aeration and post-aeration periods, and then the average durations of the five 242 observation trials $(\mathrm{n}=5)$ were compared between pre- and post-aeration periods 243 using a paired $t$-test to confirm observers' recognition of the pellets. The data 244 showed normal distribution and homogeneity of variance between pre- and post245 aeration. 
In the test trials, observers' frequency of staying near the aeration in the test

247 fish tank was used as an index of their response to aeration. The staying frequency

248 in the aeration area (which was defined as $20 \times 20 \mathrm{~cm}$ surrounding the aeration

249 stone) was counted during $2 \mathrm{~s}$ every $1 \mathrm{~min}$ of the pre-aeration and post-aeration

250 periods. Attraction to the aeration was evaluated by the staying index, calculated

251 by subtracting the frequency during pre-aeration from that during post-aeration.

252 To investigate how well the observation trials promoted transmission of response to

253 aeration, the staying index of each observation treatment was compared using a

254 Kruskal-Wallis test, and each observation treatment was compared with the

255 control treatment using Steel's multiple comparison. Some of the data lacked

256 homogeneity of variance between treatments; this is why the analyses were

257 conducted using non-parametric methods.

259 Results

260 There was a significant difference in the attraction to the demonstrator tank 261 among treatments in the observation trials (Kruskal-Wallis test: $n=8, \mathrm{X}^{2} 3,32=11.2$, $262 P<0.05)$; the attraction duration in the responding and foraging conspecific 263 treatments was significantly longer than that in the pellets observer treatment 264 (Steel-Dwass multiple comparison test: pellets vs. responding conspecific: $n=8, t=$ 265 -2.76, $P<0.05$, pellets vs. foraging conspecific: $n=8, t=2.97, P<0.05$; Fig. 2 ).

266 Furthermore, the attraction behaviour to the demonstrator tank in the responding 267 and foraging conspecific observer treatments significantly differed from the chance 268 level, but that was not the case in pellets observers or in foraging heterospecific 269 observers (one-sample Wilcoxon test; pellets: $n=8, t=6, P>0.05$, responding 270 conspecific: $n=8, t=2, P<0.05$, foraging conspecific: $n=8, t=1, P<0.05$,

271 foraging heterospecific: $n=8, t=17, P>0.05$; Fig. 2). In the nearby pellets 
272 observation treatment, the attraction duration near aeration increased from pre- to 273 post-feeding (paired t-test; $\mathrm{df}=4, t=-2.64, P<0.05$ ), suggesting that the observer

274 fish were attracted by pellets in the oval column during the observation trial.

In the test trials, there was a significant difference in staying index between treatments (Kruskal-Wallis test; $\mathrm{X}^{2} 4,37=11.5, P<0.05$ ); the staying index in the test trial in the foraging conspecific treatment was significantly different from the control treatment (Steel-Dwass multiple comparison test; foraging conspecific: $n=$ 8, $t=-2.46, P<0.05$; Fig. 3). However, there was no such difference in staying index between other treatments and the control (pellets: $n=8, t=-0.11$, responding conspecific: $\mathrm{n}=8, t=-0.00$, nearby pellets: $n=5, t=-0.54$, foraging heterospecific observer: $n=8, t=-0.50 ; P>0.05)$.

284 Discussion

285 Naïve observer fish that were given the opportunity to see a conspecific model were 286 more likely to attend to the adjacent 'demonstration' tank, regardless of whether 287 model fish was eating food pellets (foraging conspecific treatment) or not 288 (responding conspecific treatment). However, only after seeing a conspecific eating 289 food pellets near the aeration bubbles (foraging conspecific treatment) did the 290 observing fish spend more time foraging by the aeration bubbles, a reaction 291 indicative of observational learning. Merely seeing either food pellets (pellets 292 treatment) or a responding conspecific (responding conspecific treatment) near the 293 bubbles was not sufficient to encourage directed foraging by the observing fish. 294 Furthermore, seeing the 'complete' demonstration of a fish eating food pellets only 295 induced social learning when the demonstrating fish was a conspecific ( $P$. dentex), 296 not when the model was heterospecific (S. cirrhifer). 
observation of foraging conspecifics, observational learning did not occur in 299 responding conspecific observers even though observer fish watched the 300 demonstrator responding to aeration. These results imply that the observational

301 learning in this species was not imitation-that is, copying the responses of other

302 individuals. Fiorito and Scotto (1992) found that octopuses (Octopus vulgaris) chose

303 the 'right' ball through the observation of demonstrators, despite the fact that the

304 demonstrator received neither reward nor punishment in the observation trial. In

305 Laland and Williams (1997), when untrained guppies (Poecilia reticulate) were

306 given the experience of swimming with conspecific demonstrators trained to take

307 one of two equivalent routes to food, subjects preferred to use the route of their

308 demonstrator when tested alone. These behavioural transmissions were considered

309 imitations, a reflex response that was programmed to copy the demonstrator's

310 behaviour. On the other hand, the formation of observational learning in this study

311 suggested that $P$. dentex juveniles learned through recognizing a feeding 312 conspecific near the aeration.

313 Fish in the pellets observation treatment were not attracted to the pellets in

314 the adjacent demonstrator tank, so it is possible that the observer did not notice

315 the presence of the pellets during the observation trial in this treatment. This

316 finding also supports the idea that the presence of demonstrator fish would be

317 important for inducing the attention of an observer. However, in the nearby pellets

318 treatment, pellets were presented to make the observer aware of the presence of

319 food during the observation trial, and then the observer fish was attracted to the

320 pellets appearing near the aeration. These fish did not respond to aeration on the

321 test trial despite the fact that they had responded to the pellets dropped near the 322 aeration. This result suggests that ghost display conditioning was not formed in 323 this study-thus, the observer needed the presence of a demonstrator. In other 
324 words, the visual recognition of prey did not have any value as an unconditioned

325 stimulus for $P$. dentex juveniles. These findings also suggest that the foraging of 326 demonstrator fish is a substitute reward for an observer fish, which is 327 indispensable for observational learning.

328 Observation of a heterospecific demonstrator did not induce observational

329 learning in $P$. dentex juveniles. This indicates that the presence of $S$. cirrhifer did

330 not promote the awareness of $P$. dentex in the same way as a conspecific

331 demonstrator; the distinct appearance of $S$. cirrhifer may not trigger a cognitive

332 response as a model for observational learning. On the other hand, Mathis et al.

333 (1996) reported that the brook stickleback (Culaea inconstans) developed an

334 avoidance response from observing the startle response of a fathead minnow

335 (Pimephales promelas). The authors described that these species often form a

336 mixed school in the natural environment and suggested that observational

337 learning would be established within ecologically similar species, even if they are

338 not conspecifics. Further investigations would be required to elucidate interspecies

339 observational learning; for example, a morphologically and behaviourally similar

340 heterospecific such as T. japonicus could be used as a demonstrator for $P$. dentex.

341 Although some past studies on social learning in fish have focused on the

342 relation between demonstrator and observer (Duffy et al. 2009; Laland et al. 2011;

343 Pike et al. 2010), few studies have investigated the mechanism of observational

344 learning in fish. We would like to propose a potential mechanism of observational

345 learning in fish in the light of the results of the present study. First, the presence of

346 a demonstrator fish is an important factor for inducing the attention of an

347 observer, and an appropriate demonstrator is required in this regard. Second, the

348 foraging behaviour of the demonstrator is a fundamental factor. Our study

349 indicated that fish cannot acquire necessary information merely with the presence 
350 of food at the aeration or through imitating the responding behaviour to aeration of

351 a demonstrator; instead, they learn through vicarious reinforcement from a feeding 352 demonstrator.

353

354 Acknowledgment

355 We thank the two reviewers whose comments substantially improved the quality of

356 the manuscript. We also thank Drs. Fumio Takeshita and Ryosuke Ohata, who also

357 provided constructive feedback. Yamazaki Giken Co. kindly provided the $P$. dentex 358 juveniles.

359

$360 \quad$ Ethical standards

361 All experiments were performed according to the Regulations on Animal

362 Experimentation at Kyoto University. After the experiment, the fish were kept in 363 the laboratory as brood stock.

364 
365

366

367

368

369

370

371

372

373

374

375

376

377

378

379

380

381

382

383

384

385

386

387

388

389

390

References

Arai T, Tominaga O, Seikai T, Masuda R (2007) Observational learning improves predator avoidance in hatchery-reared Japanese flounder Paralichthys olivaceus juveniles. J Sea Res 58:59-64

Brown C, Laland KN (2001) Social learning and life skills training for hatchery reared fish. J Fish Biol 59:471-493

Brown C, Laland KN, Krause J (2011) Fish cognition and behavior. In: Brown C, Laland KN, Krause J (eds) Fish Cognition and Behavior, 2 $2^{\text {nd }}$ ed. Blackwell Publishing Ltd, UK, pp 1-9

Brown C, Laland KN (2011) Social learning in fishes. In: Brown C, Laland KN, Krause J (eds) Fish Cognition and Behavior, $2^{\text {nd }}$ ed. Blackwell Publishing Ltd, UK, pp 240-257

Brown C, Markula A, Laland KN (2003) Social learning of prey location in hatchery-reared Atlantic salmon. J Fish Biol 63:738-745

Bshary R, Wickler W, Fricke H (2002) Fish cognition: a primate's eye view. Anim $\operatorname{Cog} 5: 1-13$

Duffy GA, Pike TW, Laland KN (2009) Size-dependent directed social learning in nine-spined sticklebacks. Anim Behav 78: 371-375

Fiorito G, Scott P (1992) Observational learning in Octopus vulgaris. Science 256:545-547

Fukumori K, Okuda N, Yamaoka K, Yanagisawa Y (2010) Remarkable spatial memory in a migratory cardinalfish. Anim Cogn 13:385-389

Griffiths SW (2003) Learned recognition of conspecifics by fishes. Fish Fisheries 4:256-268Grosenick L, Clement TS, Fernald RD (2007) Fish can infer social rank by observation alone. Nature 445:429-432

Hopper LM, Lambeth SP, Schapiro SJ, Whiten A (2008) Observational learning in 
chimpanzees and children studied through 'ghost' conditions. P Roy Soc Lond B Bio 275:835-840

Hopper LM (2010) 'Ghost' experiments and the dissection of social learning in humans and animals. Biol Rev 85:685-701

Kelly JL, Evans JP, Ramnarine IW, Magurran AE (2003) Back to school: can antipredator behaviour in guppies be enhanced through social learning? Anim Behav 65:655-662

Kleiman DG, Eisenberg JF (1973) Comparisons of canid and felid social systems from an evolutionary perspective. Anim Behav 21:637-659

Klein ED, Zentall TR (2003) Imitation and affordance learning by pigeons (Columbia livia). J Comp Psychol 117:414-419

Laland KN, Williams K (1997) Shoaling generates social learning of foraging information in guppies. Anim Behav 53:1161-1169

Laland KN, Atton N, Webster MM (2011) From fish to fashion: experimental and theoretical insights into the evolution of culture. Philos T Roy Soc B

McGregor A, Saggerson A, Pearce J, Heyes C (2006) Blind imitation in pigeons, 366:958-968 Columba livia. Anim Behav 72:287-296

Masuda R, Tsukamoto K (1998) The ontogeny of schooling behavior in the striped jack. J Fish Biol 52:483-493

Mathis A, Chivers DP, Smith RJF (1996) Cultural transmission of predator recognition in fishes, intraspecific and interspecific learning. Anim Behav $51: 185-201$

414 Miller HC, Rayburn-Reeves R, Zentall TR (2009) Imitation and emulation by dogs using a bidirectional control procedure. Behav Process 80:109-114

416 Pike TW, Kendal JR, Rendell LE, Laland KN (2010) Learning by proportional 
Reader SM, Kendal JR, Laland KN (2003) Social learning of foraging sites and escape routes in wild Trinidadian guppies. Anim Behav 66:729-739

Shaw E (1978) Schooling fishes. Am Sci 66:166-175

Shulster S, Wohl S, Griebsch M, Klostermeier I (2006) Animal cognition: how archer fish learn to down rapidly moving targets. Curr Biol 16:378-383

Takahashi K, Masuda R, Matsuyama M, Yamashita Y (2012a) Stimulus-specific development of learning ability during habitat shift in post-recruitment stage jack mackerel. J Ethol 30:309-316

Takahashi K, Masuda R, Yamashita Y (2012b) School for learning: sharing and transmission of feeding information in jack mackerel Trachurus japonicus juveniles. Fisheries Sci 78:269-276

Tennie C, Call J, Tomasello M. (2010) Evidence for emulation in chimpanzees in social settings using the floating peanut task. PLoS ONE 5:e10544

Warner RR (1988) Traditionality of mating-site preferences in a coral reef fish. Nature 335:719-721

Webster MM, Laland KN (2008) Social learning strategies and predation risk: minnows copy only when using private information would be costly. P Roy Soc Lond B Bio 275:2869-2876

Witte K, Nobel S (2011) Learning and mate choice. In: Brown C, Laland K, Krause J (eds) Fish Cognition and Behavior, $2^{\text {nd }}$ ed. Blackwell Publishing Ltd, UK,

439 Zohar O, Terkel J (1991) Acquisition of pine cone stripping behavior in black rats 440 (Rattus rattus). Int J Comp Psychol 5:1-6 
442 Fig. 1 Schematic drawings of observational treatments. (a) Pellets observation:

443 pellets were dropped near the aeration in the demonstrator tank. (b) Responding

444 conspecific observation: a trained demonstrator fish responded to the aeration in

445 the demonstrator tank. (c) Foraging conspecific observation: a demonstrator fish

446 fed on pellets near the aeration in the demonstrator tank. (d) Nearby pellets

447 observation: a transparent plastic column was placed at the centre of the observer

448 tank, and aeration was put near the column. Pellets were dropped in the column,

449 on which the observer fish could not feed. (e) Foraging heterospecific observation: a

450 Stephanolepis cirrhifer demonstrator was fed with pellets near the aeration. (f)

451 Control: no demonstrator was provided

453 Fig. 2 Median attraction duration with demonstrator tank on the first observation

454 trial of each observation treatment. Asterisks indicate the significant differences in 455 duration from the chance level, represented by a dotted line $(7.5 \mathrm{~s}: 25 \%$ of $30 \mathrm{~s} ; P<$ 456 0.05; one-sample Wilcoxon test). Bars indicate the interquartile range $(\mathrm{n}=8$ except 457 for nearby pellets $[\mathrm{n}=5])$

459 Fig. 3 Median staying index in each treatment in the test trial. Asterisk indicates 460 that the duration significantly differed from controls $(P<0.05$; Steel multiple comparison test). Bars indicate the interquartile range ( $\mathrm{n}=8$ except for nearby

462 pellets $[\mathrm{n}=5])$ 


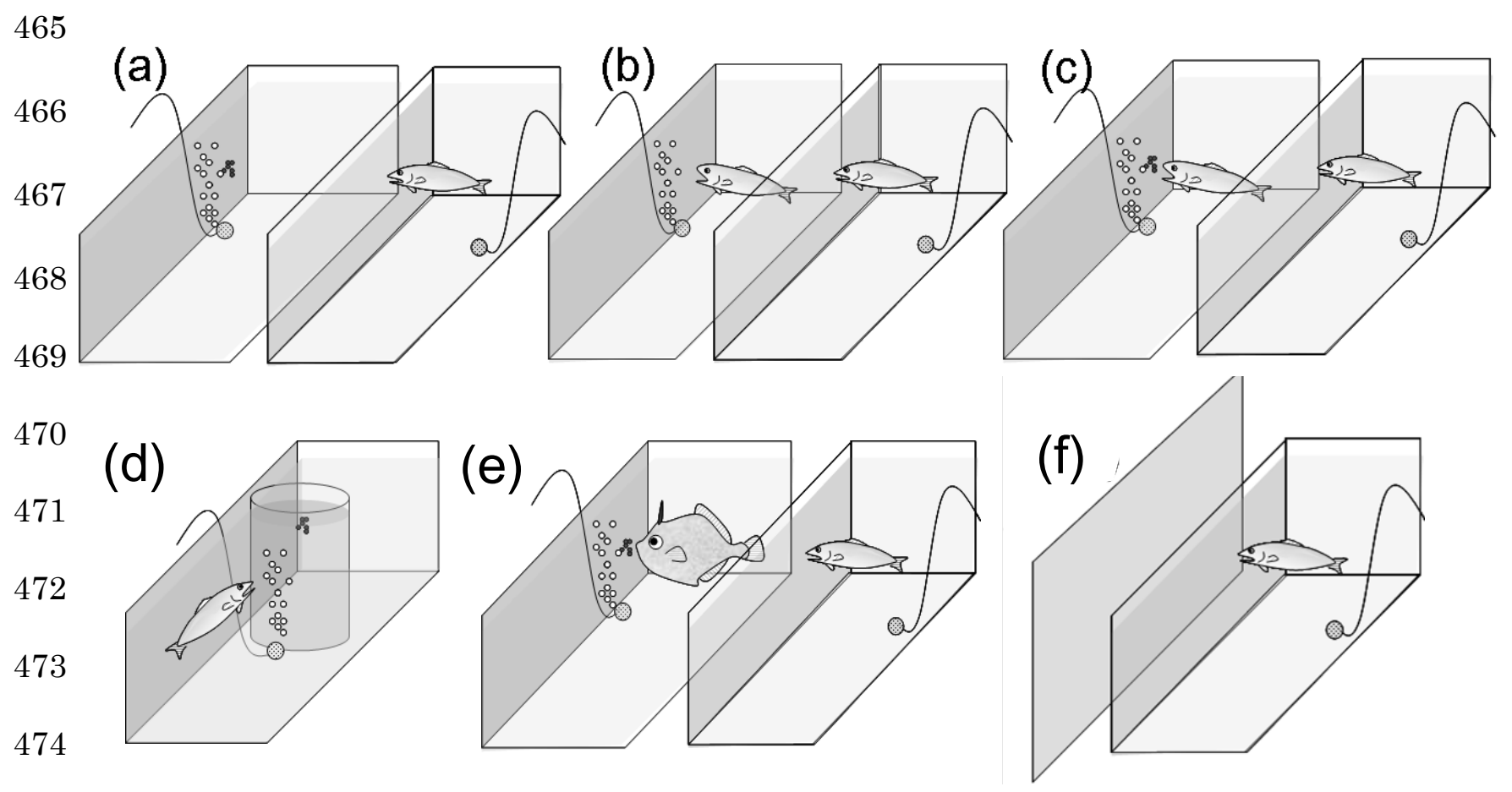

475

476 Fig. 1

477 
478

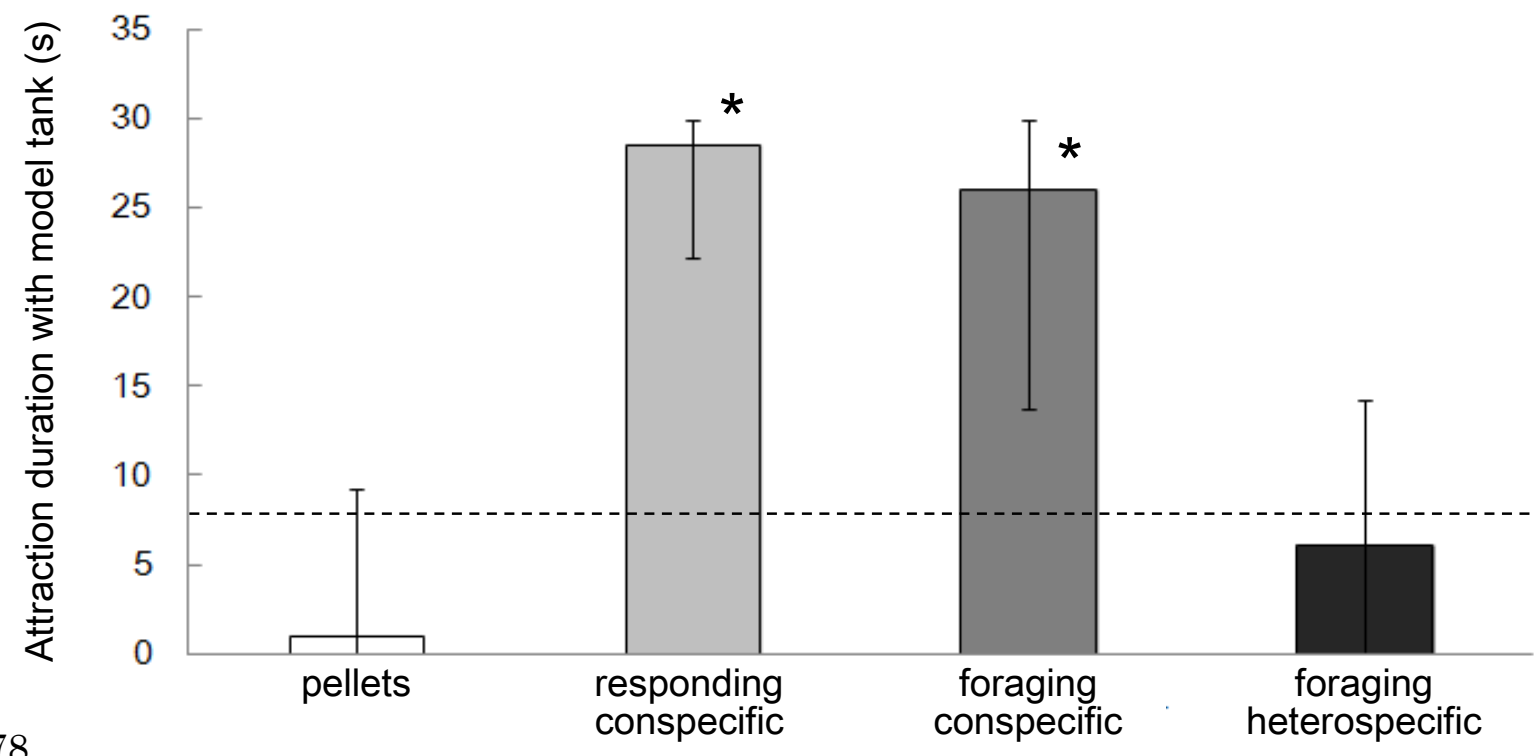

$479 \quad$ Fig. 2

480 


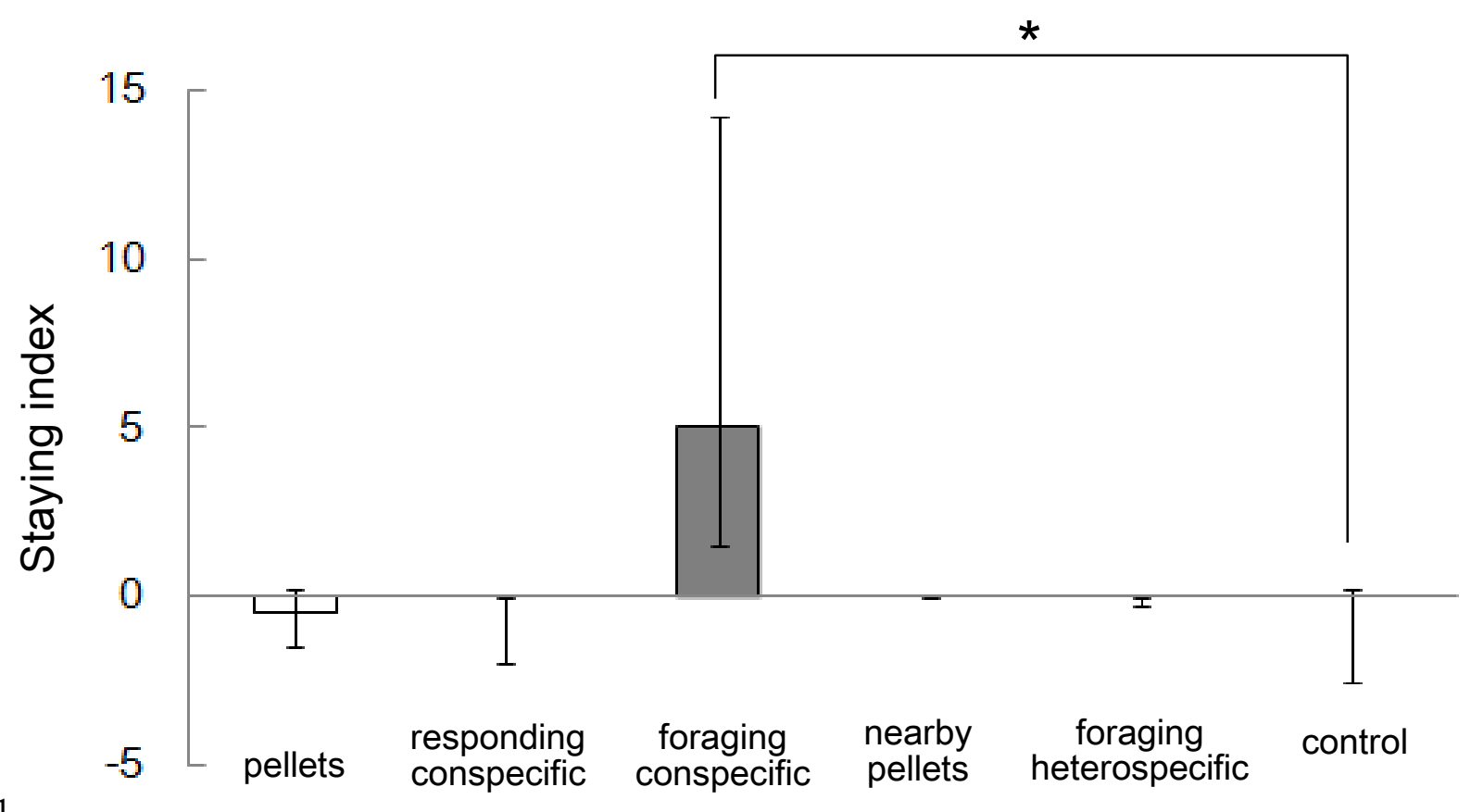

481

$482 \quad$ Fig. 3

483 